\title{
MEMBANGKITKAN EKONOMI KELOMPOK WANITA TANI (KWT) OKRA DESA SUKANEGERI DENGAN PEMBUATAN SABUN CUCI PIRING
}

\author{
Dian Risma Puteri ${ }^{1}$, Fika Yunita Sari², Vega Nurmalita Sari ${ }^{3}$, Wahyu Dwi Amansyah ${ }^{4}$, \\ Wahyu Rahmatulloh ${ }^{5}$. \\ 1, Jurusan Ilmu Pemerintahan, Fakultas Ilmu Sosial dan Ilmu Politik, Universitas Lampung \\ ${ }^{2}$ Jurusan Hukum Pidana, Fakultas Hukum, Universitas Lampung \\ ${ }^{3}$ Jurusan Agroteknologi, Fakultas Pertanian, Universitas Lampung \\ ${ }^{4}$ Jurusan Matematika, Fakultas Matematika Dan Ilmu Pengetahuan Alam, Universitas Lampung \\ ${ }^{5}$ Jurusan Teknik Mesin, Fakultas Teknik, Universitas Lampung \\ Penulis Korespodensi : wahyuamansyah9@gmail.com
}

\begin{abstract}
Abstrak
Kelompok Wanita Tani (KWT) OKRA adalah sebuah organisasi masyarakat yang ada didesa Sukanegeri Kecamatan Bangunrejo Kabupaten Lampung Tengah. Dimana para anggotanya adalah masyarakat sekitar yang memiliki keinginan untuk mewujudkan tujuan bersama. Tujuan didirikannya KWT OKRA adalah untuk mengembangkan keterampilan terutama pada sektor pertanian dan sektor ekonomi kreatif masyarakat. Pada salah satu pelaksanaan Program Kerja Kuliah Kerja Nyata(KKN) Universitas Lampung Periode 1 Tahun 2021 di Desa Sukanegeri Kecamatan Bangunrejo Kabupaten Lampung Tengah adalah sosialisasi sekaligus pembuatan Sabun cuci piring guna meningkatkan keterampilan warga dan juga meningkatkan aksesibilitas warga terhadap sabun cuci piring. Sabun cuci piring merupakan kebutuhan skunder dimana sabun cuci piring selalu dibutuhkan setiap saat untuk semua kalangan masyarakat. Maka dari itu Pembuatan sabun cuci piring adalah satu produksi yang dapat membangkitkan ekonomi KWT OKRA Desa Sukanegeri.
\end{abstract}

Kata kunci: kwt okra, sabun cuci piring, ekonomi

\begin{abstract}
OKRA's Women's Farmers Group (KWT) is a community organization in Sukanegeri village, Bangunrejo District, Central Lampung Regency. Where the members are the surrounding community who have a desire to achieve common goals. The purpose of establishing KWT OKRA is to develop skills, especially in the agricultural sector and the community's creative economy sector. One of the implementations of the University of Lampung Real Work Lecture Work Program (KKN) Period 1 Year 2021 in Sukanegeri Village, Bangunrejo District, Central Lampung Regency, is the socialization and manufacture of dish soap to improve the skills of residents and also increase the accessibility of residents to dish soap. Dish washing soap is a skunder need where dish soap is always needed for all people. Therefore, making dish soap is a production that can raise the economy of KWT OKRA in Sukanegeri Village..
\end{abstract}

Key Word : Okra kwt, dish soap, economy 


\section{Jurnal Pengabdian Kepada Masyarakat BUGUH}

Dipublikasikan

Badan Pelaksana Kuliah Kerja Nyata

Universitas Lampung

Sekretariat Badan Pelaksana Kuliah Kerja Nyata, Universitas Lampung.

Jl. Prof. Dr. Soemantri Brojonegoro No. 1, Bandar Lampung 35145.

\section{PENDAHULUAN}

Desa Sukanegeri adalah salah satu desa yang berada dalam wilayah hukum Kecamatan Bangunrejo Kabupaten Lampung Tengah Provinsi Lampung. Wilayah yang subur dan luas menjadikan desa sukanegeri kaya akan hasil bumi disektor pertanian, Desa Sukanegeri dengan luas wilayah 260 Hektar, dihuni oleh 435 KK dan 1377 jiwa., Desa Sukanegeri terus meningkatkan hasil pertanian dengan menggerakkan sekelompok wanita tani. Kelompok Wanita Tani atau biasa disingkat dengan KWT merupakan sebuah wadah yang menghimpun wanita-wanita tani didesa Sukanegeri, KWT dibentuk sebagai upaya pelibatan kaum perempuan secara langsung dalam usaha peningkatan hasil usaha pertanian. Seperti menjadi bagian dari motivator dalam adopsi dan pengenalan tehnologi tani. Salah satu tanaman yang menjadi komoditas utama KWT sukanegeri adalah OKRA(Abelmoschus esculentus) Dengan menanam tumbuhan Okra, wanita tani desa sukanegeri dapat berperan penting dalam mengingkatklan ekonomi rakyat dari hasil berbagai macam olahan makanan berbahan pokok tanaman Okra. Okra merupakan tumbuhan yang sangat bermanfaat bagi kesehatan. Adapun manfaat tanaman Okra yaitu dapat menurunkan kadar gula darah dan kolestrol, mengatasi konstipasi, mencegah kanker usus, mencegah radikal bebas dan lain-lain. Maka dari sejarah pengalam-pengalaman kegiatan itulah KWT yang ada didesa Sukanegeri diberi nama KWT OKRA Sukanegeri. Minggu, 21 Februari 2021 telah terlaksana program kerja Sosialisasi sekaligus Pembuatan sabun cuci piring dari kegiatan Kuliah Kerja Nyata (KKN) Unila Periode 1 Tahun 2021. Kegiatan ini bertempatan di Halaman Balai Desa Sukanegeri bersama dengan ibu-ibu senam lansia dan ibu-ibu yang sebagian besar adalah pengurus KWT OKRA Sukanegeri. Tujuan dari kegiatan ini adalah memberikan informasi pengetahuan yang telah mahasiswa dapatkan dari kegiatan kampus agar dapat tersampaikan dan bermanfaat untuk masyarakat desa sukanegeri terutama kepada Kelompok Wanita Tani OKRA desa Sukanegeri,.

Sabun adalah bahan yang digunakan untuk mencuci, baik pakaian, perabotan, badan, dan lain-lain yang terbuat dari campuran alkali (natrium atau kalium hidroksida), dan trigliserida dari asam lemak rantai karbon C16 (Zulkifli dan Estiasih, 2014) melalui reaksi saponifikasi atau disebut juga reaksi penyabunan pada suhu 80- 100 C (Jongko, 2009). Dalam proses ini asam lemak akan terhidrolisa oleh basa membentuk gliserin dan sabun mentah. Sabun dapat menghilangkan kotoran dan minyak karena struktur kimia sabun terdiri dari bagian yang bersifat hidrofil pada rantai ionnya, dan bersifat hidrofobik pada rantai karbonnya. Karena adanya rantai hidrokarbon, sebuah molekul sabun secara keseluruhan tidaklah benar-benar larut dalam air. Namun sabun mudah tersuspensi dalam air karena membentuk misel METANA Juni 2018 Vol. 14(1):15-18 16 Produksi Sabun Cuci Piring Sebagai Upaya Peningkatkan (R. Amalia et al.) (micelles), yakni segerombolan (50-150) molekul yang rantai hidrokarbonnya mengelompok dengan ujung- ujung ionnya yang menghadap ke air (Fessenden dan Fessenden, 1992). Dalam menghilangkan kotoran dan minyak, bagian yang bersifat hidrofobik pada sabun akan larut dalam minyak dan mengepung kotoran minyak, sedangkan bagian hidrofilik akan terlepas dari permukaan yang dibersihkan dan terdispersi dalam air sehingga dapat dicuci (Djatmiko dan Widjaja, 1984). Secara historis, perkembangan produksi jagung di Indonesia cenderung mengalami peningkatan rata-rata sekitar 5,26\% per tahun pada 10 tahun terakhir ini. Hal ini berbanding lurus dengan peningkatan produktivitas rata-rata sekitar 4,30\% per tahun. Luas areal pada periode yang sama juga mengalami peningkatan rata-rata sebesar $0,83 \%$ per tahun. Hal ini menyebabkan surplus jagung meningkat rata-rata sebesar $111 \%$ atau sekitar 1,2 juta ton per tahun. Kenaikan ini dapat diindikasikan karena 18 juta penduduk di Indonesia menjadikan jagung sebagai makanan pokok. (Subandi, 1988) dalam (Aldillah, 2017) . Komoditas jagung dapat dikonsumsi oleh masyarakat dalam berbagai bentuk olahan, tidak hanya sebagai pangan pokok tetapi juga sebagai lauk-pauk, makanan selingan, dan bahan setengah jadi yang dihasilkan oleh beragam jenis industri dan skala usaha(Ariani dan Pasandaran 2005) dalam (Aldillah, 2017)

Sabun sebagai salah satu kebutuhan utama untuk mendapatkan standar kebersihan yang baik dalam kehidupan sehari-hari termasuk dalam kebutuhan pokok, tetapi sabun tidak termasuk dalam kelompok 


\section{Jurnal Pengabdian Kepada Masyarakat BUGUH}

Dipublikasikan

Badan Pelaksana Kuliah Kerja Nyata

Universitas Lampung

Sekretariat Badan Pelaksana Kuliah Kerja Nyata, Universitas Lampung.

Jl. Prof. Dr. Soemantri Brojonegoro No. 1, Bandar Lampung 35145.

kebutuhan primer. Pemenuhan akan sabun seringkali dianggap sebagai kebutuhan sekunder, karena kebutuhan primer (sandang, pangan, papan) merupakan kebutuhan yang wajib untuk dipenuhi setiap hari. Konsumsi sabun yang terus menerus setiap harinya, menyebabkan kebutuhan pengadaan sabun yang membutuhkan biaya yang tidak sedikit. Dalam menjalankan usaha pembuatan jajan sederhana, sabun yang selama ini digunakan untuk mencuci piring adalah sabun colek dengan harga $\mathrm{Rp} 2.600$,- per sachet per hari. Penyediaan sabun sachet untuk 1 bulan membutuhkan biaya sebanyak Rp 52.000,- Hal ini menunjukkan bahwa masyarakat harus menyediakan dana minimal Rp 52.000,- per bulan untuk pengadaan sabun yang diperlukan untuk membersihkan peralatan memasak.

Tujuan kegiatan kegiatan sosialisasi dan pembuatan sabun cuci piring ini adalah untuk memberikan pengetahuan dan pelatihan tentang pembuatan sabun cuci piring cair sekaligus untuk membantu mengurangi pengeluaran masyarakat untuk pembelian sabun dengan harga yang mahal. Produksi sabun cuci piring secara massal juga dapat menciptakan peluang usaha baru.

\section{BAHAN DAN METODE}

Kegiatan pengabdian masyarakat meliputi identifikasi permasalahan yang muncul pada masyarakat sesuai dengan kompetensi masyarakat bersangkutan. Permasalahan tersebut yang selanjutnya dikaji dan dicarikan solusi. Metode pendekatan untuk dapat menyelesaikan permasalahan dalam kegiatan ini menggunakan metode Participatory Action Research (PAR). Solusi yang ditawarkan pada kegiatan kewirausahaan pada masyarakat ini berupa pemberian penyuluhan dengan materi yang telah ditentukan.

\section{- Alat dan bahan}

Bahan yang digunakan meliputi Teksapon, SLS(natrium lauril eter sulfat), $\mathrm{NaCl}$ (garam), pewarna dan pewangi. Peralatan yang digunakan meliputi 3 buah ember besar, kayu, gayung, corong, timbangan, dan botol.

\section{- Formula Sabun Cuci Piring}

Dirancang formula sediaan sabun cuci piring di formulasi dari 1.Teksapon(Bahan kimia untuk mengangkat lemak dan kotoran), 2.SLS berfungsi untuk menghasilkan busa dan membersihkan kotoran, 3. $\mathrm{NaCl}$ (garam) befungsi untuk mengentalkan cairan, 4. Pewarna sebagai pewarna sabun, 5. Pewangio berfungsi untuk pewangi.

\section{- Metode Pelaksanaan}

Metode yang digunakan dalam kegiatan ini yaitu dengan memberikan informasi, pelatihan, dan pendampingan kepada Kelompok Wanita Tani (KWT) Desa Sukanegeri. Tahap pelaksanaan sebagai berikut: 1) Sosialisasi/transfer informasi mengenai langkah-langkah pembuatan sabun cuci piring. 2) praktek pembuatan pembuatan sabun cuci piring.

\section{HASIL DAN PEMBAHASAN}

Hasil dari tahap pelaksanaan kegiatan KKN Mandiri Putera Daerah Periode 1 Tahun 2021 Universitas Lampung di Desa Sukanegeri Kecamatan Bangunrejo Kabupaten Lampung Tengah Lampung adalah sebagai berikut:

\section{Tahap Persiapan}

Tahap persiapan, mahasiswa KKN Mandiri Putera Daerah Periode 1 Tahun 2021 Universitas Lampung di Desa Sukanegeri Kecamatan Bangunrejo Kabupaten Lampung Tengah berkoordinasi dengan aparatur desa Sukanegeri dan Kelompok Wanita Tani (KWT) OKRA Sukanegeri terkait dengan jadwal pelakanaan kegiatan KKN. 


\section{Jurnal Pengabdian Kepada Masyarakat BUGUH}

Dipublikasikan

Badan Pelaksana Kuliah Kerja Nyata

Universitas Lampung

Sekretariat Badan Pelaksana Kuliah Kerja Nyata, Universitas Lampung. Jl. Prof. Dr. Soemantri Brojonegoro No. 1, Bandar Lampung 35145.

\section{Pelaksanaan Sosialisasi dan Pembuatan Sabun cuci piring}

Kegiatan ini diawali dengan sosialisasi tentang pembuatan sabun cuci piring. Kegiatan ini dilakukan secara bertatap muka langsung yang dihadiri oleh ibu-ibu kelompok wanita tani (KWT). Transefer informasi yang dilakukan berupa memberitahu bagaimana proses pengenalan bahan dan alat yang diperlukan untuk membuat sabun cuci piring, dan dilanjutkan dengan praktik pembuatan sabun secara langsung.

Proses pembuatan sabun cuci piring diawali dengan pencampuran teksapon seberat 1 kilogram dengan air 7 Liter pada ember pertama, lalu diaduk hingga mencampur antara air dengan Teksapon, kemudian pada tahap kedua masukan air dengan takaran 4 Liter dicampur dengan SLS Seberat 0,5 Kilogram, lalu diaduk hingga merata, lalu pada tahan ketiga masukan garam seberat 1 Kilogram dicampur dengan air 4 Liter pada ember ketiga kemudian aduk hingga meralut. Pada tahap keempat campurkan pewarna secukupnya dengan air dalam botol aqua 600 Mililiter kemudian kocok hingga mencampur. Dalam praktik pembuatan sabun cuci piring ini dibantu oleh ibu-ibu Kelompok Wanita Tani dalam pengadukannya, sehinggga setelah 15 menit berlalu, semua bahan yang telah dicampurkan dan diaduh dimasing-masing ember sudah siap untuk disatukan. Maka langkah menyatukan dari masing-masing larutan ini pun dimulai, campurkan larutan teksapon, SLS dan Pewarna dalam satu ember kemudian aduh lagi secukupnya, jika sudah masukan larutan garam sekaligus Pewangi kemudian aduk lagi hingga merata, setelah sabun sudah merata maka artinya sabun cuci piring dinyatakan sudah jadi, dan sudah bisa digunakan sebagaimana mestinya.
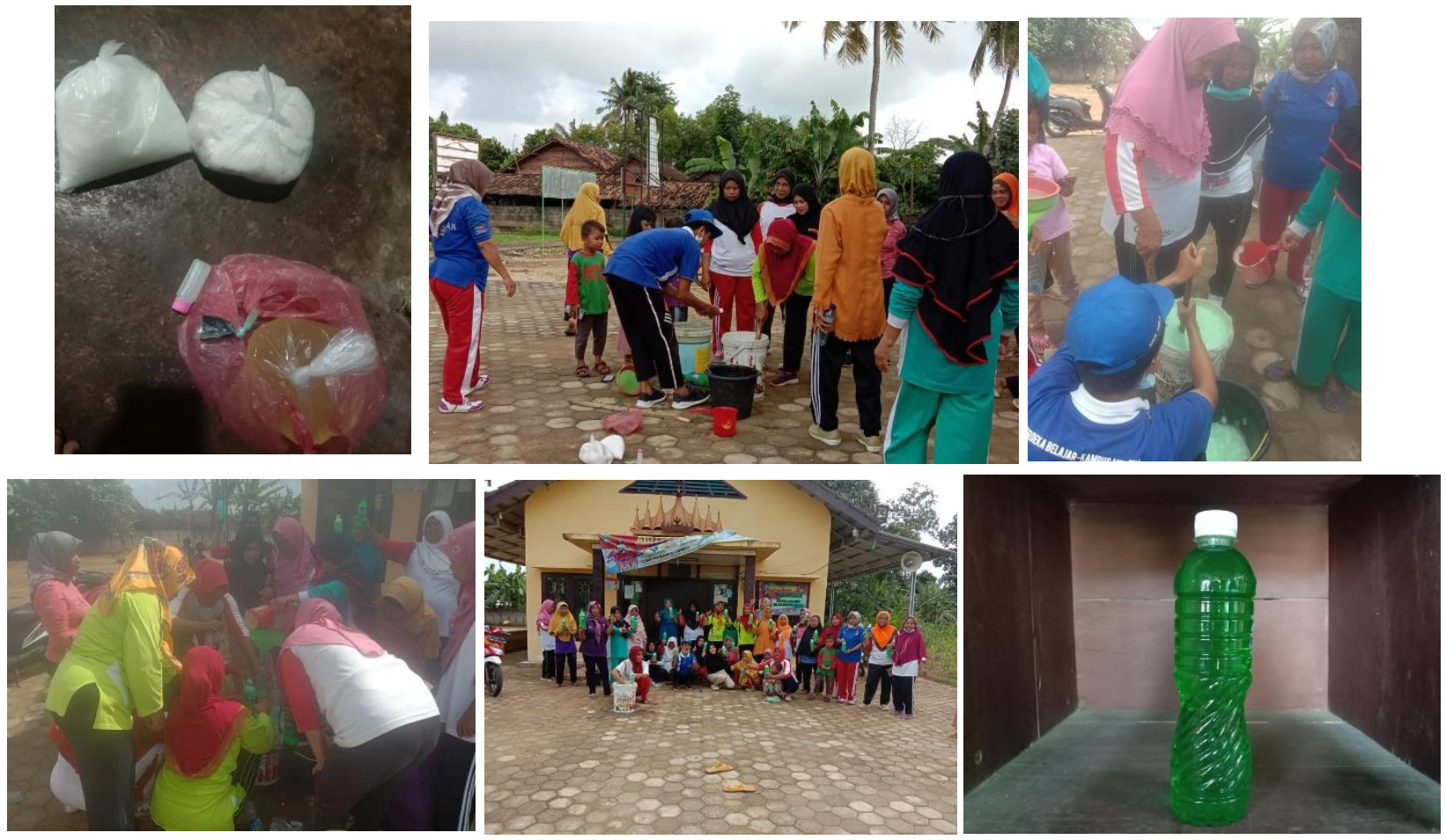

Gambar 1 Kegiatan pembuatan sabun

Setelah proses pembuatan selesai kemudian sabun dikemas menggunakan kemasan botol plastik. Tarakaran per botol sebanyak 600 Mililiter. Penggunaan kemasan botol plastik diharapkan dapat menarik perhatian pembeli. Penggunaan kemasan botol plastik ini konsumen dapat melihat detail sabun cuci piring. Sabun cuci piring dijual dengan harga Rp5.000 /pcs. Proses pengemasan yang dibantu oleh ibu-ibu Kelompok Wanita Tani dilaksanakan di balai Desa Sukanegeri. 


\section{Jurnal Pengabdian Kepada Masyarakat BUGUH}

Dipublikasikan

Badan Pelaksana Kuliah Kerja Nyata

Universitas Lampung

Sekretariat Badan Pelaksana Kuliah Kerja Nyata, Universitas Lampung. Jl. Prof. Dr. Soemantri Brojonegoro No. 1, Bandar Lampung 35145.

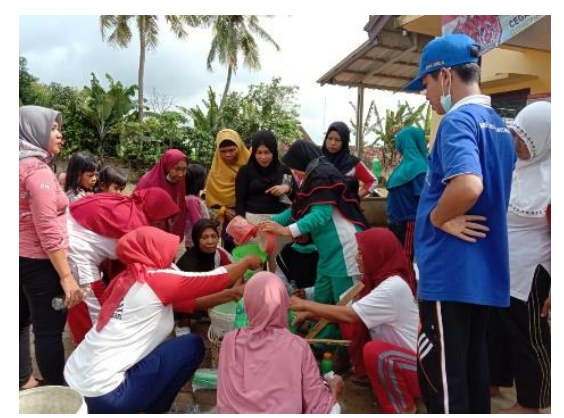

Gambar 2 Pengemasan Sabun cuci piring Bersama Ibu KWT

Kualitas yang ditawarkan dari sabun cuci piring ini menurut para panelis yang telah mencoba produk sabun cuci piring ini memiliki khualitas yang hampir sama dengan sabun cuci kemasan pada umumnya yang dijual dipasar atau warung-warung, kekurangan yang disampaikan adalah kurangnya busa ketika sedang digunakan untuk mencuci piring. Hal ini dikarenakan kandungan SLS pada sabun cuci piring rendah. Menurut Siyam Khodiyah (2021), kandungan SLS yang tinggi pada sabun cuci piring akan merangsang produksi busa naik dan menghasilkan busa yang banyak. Dengan demikian produksi sabun cuci piring ini sangat efisien untuk dijadikan komoditas baru demi meningkatkan ekonomi kreatif masyarakat terutama untuk Kelompok Wanita Tani OKRA desa Sukanegeri.dan sangat cocok untuk diperjual belikan dikalangan masyarakat desa maupun pasar tentu tidak luput dengan managemen kewirausahaan.

Kewirausahaan adalah suatu kemampuan untuk mengelola sesuatu yang ada di dalam diri seseorang untuk dimanfaatkan dan ditingkatkan agar lebih optimal (baik) sehingga bisa meningkatkan taraf hidup di masa mendatang (Meredith, 2002). Menurut Aprijon (2013) salah satu faktor pendorong pertumbuhan kewirausahaan disuatu negara terletak pada peranan universitas melalui penyelenggaraan pendidikan kewirausahaan. Oleh karena itu, perlu dibina kepribadian individu yang sangat mempengaruhi keberhasilan usaha. Dengan memiliki jiwa pemimpin, sikap mental untuk menghadapi segala resiko dan tantangan dalam hidupnya

Melalui penerapan teknologi tepat guna yang sederhana dalam pelatihan ini, diharapkan dapat diperoleh pemberdayaan masyarakat dengan peningkatan keterampilan yang bermanfaat. Teknologi sederhana ini dapat diterapkan oleh masyarakat secara umum. Teknologi ini juga diharapkan menjadi pemicu tumbuhnya semangat meningkatkan ekonomi KWT melalui kreatifitas masyarakat yang lain untuk setidaknya mencukupi kebutuhan sabun cuci piring.

Keahlian masyarakat sesudah adanya transfer metode pembuatan sabun cair diharapkan: (i) mampu membuat sabun cair yang disertai dengan pemahaman dasar akan sabun; (ii) mampu mengatur (me-manage) efisiensi maupun efektifitas penggunaan sabun cair agar tidak boros dalam pemakaiannya; (iii) mampu mengkoordinasikan sistem/cara pembuatan sabun di lingkungan RT; (iv) mampu menjadikan sabun sebagai terobosan untuk memperoleh tambahan uang keluarga; (v) mampu menghitung keuntungan yang dapat diperoleh dengan memanfaatkan peluang wirausaha. Dari kegiatan yang dilakukan, masyarakat memperoleh luaran produk barang, berupa sabun cuci piring cair secara mandiri untuk kapasitas 600 Mil6liter, yang dihasilkan sesuai dengan metode yang ditawarkan 


\section{Jurnal Pengabdian Kepada Masyarakat BUGUH}

Dipublikasikan

Badan Pelaksana Kuliah Kerja Nyata

Universitas Lampung

Sekretariat Badan Pelaksana Kuliah Kerja Nyata, Universitas Lampung. Jl. Prof. Dr. Soemantri Brojonegoro No. 1, Bandar Lampung 35145.

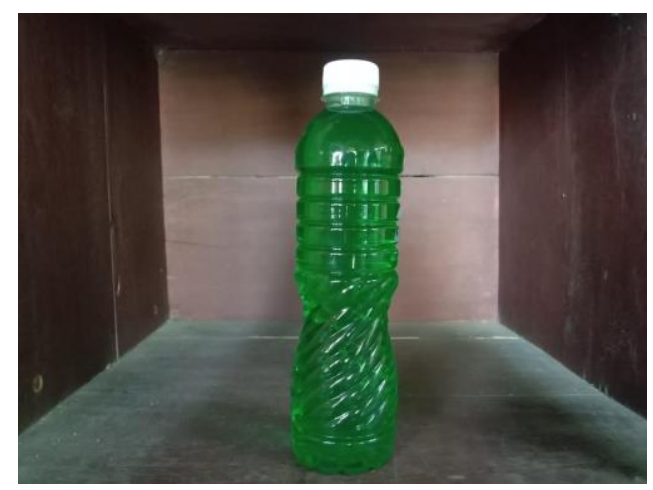

Gambar 3 Produk sabun

\section{Analisis Ekonomi Usaha Pembuatan Sabun Cuci Piring}

Harga satu pak bahan pembuat sabun dengan kapasitas 16 Liter adalah Rp 85.000,-. Keuntungan yang diperoleh dalam sekali memproduksi sebesar Rp. 60.000,- atau sekitar 51\%. Keuntungan tersebut belum termasuk biaya kemasan

Berdasarkan proses kegiatan yang telah dilakukan, Kelompok Wanita Tani (KWT) OKRA Sukanegeri memahami proses pembuatan sabun cuci piring hingga siap dipasarkan berjalan sesuai dengan perencanaan. Apabila usaha ini dapat dikembangkan dengan baik maka akan berdampak pada produktivitas masyarakat dan dapat memperbaiki perekonomian Organisasi Kelompok Wani Tani OKRA Sukanegeri

Proses pemasaran produk menurut Jatmiko et al (2015), yang perlu diperhatikan adalah kualitas produk. Kualitas produk yang perlu dijaga agar tidak mengecewakan konsumen yaitu dengan menerapkan 5P.

5P tersebut yaitu:

1. Product (produk) harus memiliki cirri khas yang berbeda dengan produk lainnya.

2. Price (harga) yang ditawarkan relative murah

3. Place (tempat), namun tergantuk jenis produk yang dipasarkan

4. Promotion (promosi) bertujuan mengenalkan produk kepada pelanggan

5. Person (penjual) bersikap ramah, sopan, menghargai pelanggan, dan berpenampilan rapi.

Kegiatan pengadian masyarakat oleh mahasiswa KKN ini diharapkan mahasiswa dapat mengembangkan bisnis yang memanfaatkan bahan-bahan yang mudah dijangkau untuk menciptakan suatu barang yang bernilai, bermanfaat bahkan bernilai jual tinggi seperti sabun cuci piring ini. Mengembangkan bisnis bagi mahasiswa dapat memberikan nilai tambah bagi mahasiswa itu sendiri. Nilai tambah yang dapat diterima yaitu memiliki usaha jika nantinya tidak ingin bekerja di suatu perusahaan atau lembaga, menambah keuangan pribadi, selin itu jika mendaftar kerja mudah diterima.

\section{Kesimpulan}

Dalam pelatihan pembuatan sabun cuci piring dapat diambil kesimpulan bahwa kegiatan dapat berjalan dengan lancer sesuai dengan yang direncanakan. Kegiatan ini dapat meningkatkan pengetahuan dan ketrampilan dalam pembuatan sabun cuci piring yang dapat dikonsumsi pribadi maupun dikomersilkan

\section{Ucapan Terima Kasih}

Terimakasih kepada teman-teman KKN Desa 227 Putera Daerah Periode 1 Tahun 2021, tanpa kalian produk ini tidak akan ada. Terimakasih kepada Dosen Jurusan Kimia yang telah memberikan Ilmu Pengetahuan cara 


\section{Jurnal Pengabdian Kepada Masyarakat}

\section{BUGUH}

Dipublikasikan

Badan Pelaksana Kuliah Kerja Nyata

Universitas Lampung

Sekretariat Badan Pelaksana Kuliah Kerja Nyata, Universitas Lampung. Jl. Prof. Dr. Soemantri Brojonegoro No. 1, Bandar Lampung 35145.

pembuatan sabun sekaligus menyediakan bahan-bahan sabun cuci piring, Terimakasih kepada aparatur Desa Sukanegeri yang telah mengizinkan kami untuk melaksanakan kegiatan KKN serta telah percaya kepada kami, bahwa kami dapat mengenalkan dan memberikan sedikit ilmu cara pembuatan sabun cuci piring menjadi produk yang memiliki nilai jual yang lebih tinggi.

\section{Daftar Pustaka}

Apriyani, D. 2013. Formulasi Sediaan Sabun Mandi Cair Minyak Atsiri Jeruk Nipis (Citrus aurantifolia) Dengan Cocamid Dea Sebagai Surfaktan. Universitas Muhammadiyah Surakarta (Doctoral dissertation)

Fessenden, R. J. \& Fessenden, J. S. 1992. Kimia Organik, Jilid 2, Edisi ketiga. Penerbit Erlangga, Jakarta

Meredith, G. 2003. Kewirausahaan Teori dan Praktek. Jakarta : Pustaka Binaman Pressindo

Tanjung, D.A., 2017. Pelatihan Pembuatan Sabun Cair dan Shampoo Pencuci Mobil. Jurnal Prodikmas Hasil Pengabdian Masyarakat. 2(1):41-45.

Wijana, S., Sumarjo \& Harnawi, T., 2009. Studi pembuatan sabun mandi cair dari daur ulang minyak goreng bekas (Kajian pengaruh lama pengadukan dan rasio air: sabun terhadap kualitas). Jurnal Teknologi Pertanian, 10(1):54-61. 